ISSN 1112-9867

http://www.jfas.info

\title{
DESIGNING CELLULAR MANUFACTURING SYSTEM UNDER RISK CONDITIONS
}

\author{
O. Arghish \\ Department of Industrial Engineering, Gachsaran Branch, Islamic Azad University \\ Gachsaran, Iran
}

Published online: 15 May 2016

\begin{abstract}
This paper develops a mathematical modeling to design a cellular manufacturing system. In addition some of the total or portion of the demand of the part types can be subcontracted.. In order to designing the optimal CMS, we needs to detrmined a plan to produce and subcontract parts at a minimum cost and to mitigate the impact of sub-contracting risk. Thus we propose a mixed integer programming approach to decision making and incorporate subcontracting risk . To control the risk of sub-contracting (cost), the two popular percentile measures of risk are applied: value-at-risk and conditional value-at-risk. This model is capable of optimizing production cost of parts and calculating value-at-risk of subcontracting cost simultaneously. A numerical example is solved to verify the performance of the proposed model.
\end{abstract}

Key words: Cellular manufacturing system, sub contract, Risk management, Conditional value-at-risk.

Author Correspondence, e-mail: omid.arghashi@gmail.com

doi: http://dx.doi.org/10.4314/jfas.v8i2s.12

\section{INTRODUCTION}

Manufacturing industries are under pressure from the increasingly-competitive global marketplace. With increased global competition and shorter product life cycles, there have been demands for mid-volume and mid-variety product mixes. Job shops and flow lines does not provide adequate throughput with high product volumes and products variety. Cellular manufacturing system (CMS) provides the combined advantages of both Job-Shop and Flow 
Line Manufacturing. Cellular manufacturing systems (CMSs) are used when both production volume and product variety are at medium level.CMS is an application of GT in which types of machines are grouped into cells so that each cell is dedicated to the manufacture of some specific part families. This paper is structured as follows. In the next section presents Literature Review. The Problem description is developed in Section 3. Section 4 presents Computational examples and Discussion of results and Section 5 concludes the paper.

\subsection{Group technology}

Group technology is a principle, which decomposes a global system into several subsystems, which are easier to manage than the entire system.Applied to manufacturing, this principle is the base of the design of production cells.[1]

\subsection{Cellular manufacturing system}

Cellular manufacturing systems (CMS) are one of the alternatives for the production environment with high variety and high volume of products. The main goal of CMS is to minimize the throughput time, setup cost and also the material handling costs in the shop floor[2]. Reported benefits of CMS include increases in throughput coupled with reductions in setup times and costs, cycle times, work-in-process inventory levels, material handling times and costs, factory space requirements, product defect rates, and machine idle times.[3]

\subsection{Cell formation}

The design of CMSs has been called cell formation (CF), part family/machine cell (PF/MC) formation, and manufacturing cell design. Given a set of part types, processing requirements, part type demand and available resources (machines, equipment, etc.,), the design of CMSs consists of the following three key steps[4]:

(i) Part families are formed according to their processing requirements.

(ii) Machines are grouped into manufacturing cells.

(iii) Part families are assigned to cells.

\subsection{Risk management}

Risk management in general is described as the identification and analysis of risks as well as their control[5]. From the mathematical perspective, risk management is a procedure for shaping a loss distribution.[6]value-at-risk ( $\mathrm{VaR})$ and Conditional value-at-risk (CVaR) are two popular tools for managing risk, but the emphasis is on Conditional Value-at-Risk (CVaR), which is known also as Mean Excess Loss, or Tail VaR. .[7]

\subsubsection{Definitions of $\mathrm{VaR}$ and $\mathrm{CVaR}$}

Let $\mathrm{X}$ be a random variable with the cumulative distribution function $\mathrm{F}_{\mathrm{X}}(\mathrm{z})=\mathrm{P}\{\mathrm{X} \leq \mathrm{z}\}$. $\mathrm{X}$ have meaning of loss or profit. [6] 


\section{Definition of VaR}

The VaR of $\mathrm{X}$ with confidence level $\alpha \in[0,1]$ is $\operatorname{VaR}_{\alpha}(\mathrm{X})=\min \{\mathrm{z} \mid \mathrm{P}\{\mathrm{X} \leq \mathrm{z}\} \geq \alpha\}$ By definition, $\operatorname{VaR} \alpha(\mathrm{X})$ is a lower $\alpha$-percentile of the random variable $\mathrm{X}$.[ 6]

\section{Definition of (CVaR)}

For random variables with continuous distribution functions, $\mathrm{CVaR}_{\alpha}(\mathrm{X})$ equals the conditional expectation of $\mathrm{X}$ subject to $\mathrm{X} \geq \operatorname{VaR}_{\alpha}(\mathrm{X})$. [6]The graphical representation of $\mathrm{VaR}, \mathrm{CVaR}$, and VaR, CVaR Deviation, Max Loss, and Max Loss Deviation are shown in Figure 1.[6]

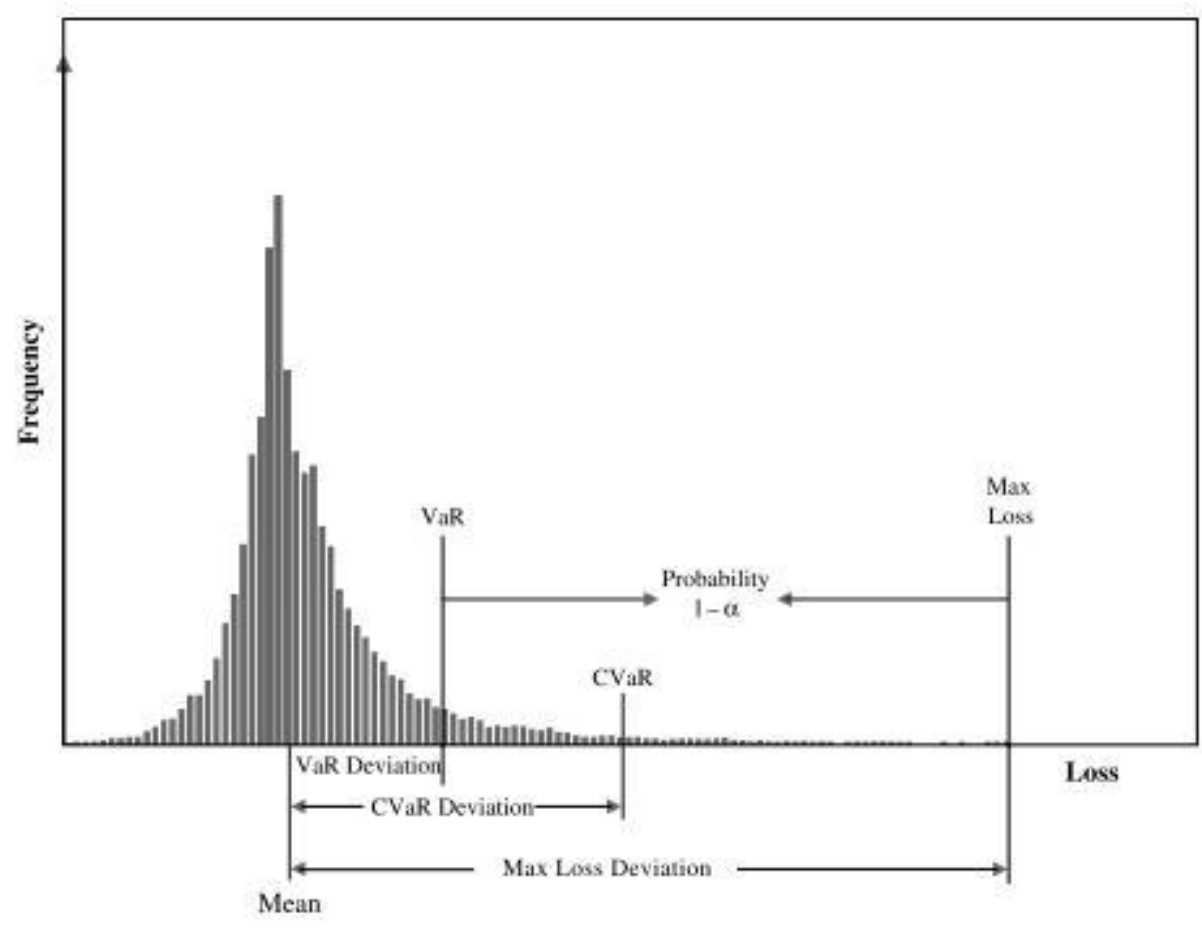

Fig.1. [ 6]

\section{LITERATURE REVIEW}

Singh [8] has reviewed the many structured approaches such as graph theoretic methods, neural networks and mathematical and heuristic methods to the Cell Formation Problem. Atmani, Lashkari, and Caron [9] introduced a model for simultaneous cell formation and operation allocation. Singh, [10] has shown CM is also effective in implementing flexible manufacturing systems.Wemmerlov \& Johnson, [11] have reviewed Successful CM implementations at 46 user plants. Chen, [12] proposed a mathematical programming for dynamic cellular manufacturing. Selim et al. [13] have categorized the approaches as cluster analysis, graph partitioning, descriptive procedures , mathematical programming, artificial intelligence approaches. CM scheduling problems introduced by Lockwood, Mahmoodi, and Mosier[14]. Production planning in CM systems proposed by Chen [15]. Schaller, Erenguc, and Vakharia [16] introduced an integer programming model to CM planning. N. Safaei and 
R. Tavakkoli-Moghaddam[2] proposed an integrated mathematical model of the multi-period cell formation and production planning in a dynamic cellular manufacturing system (DCMS) with the aim of minimizing machine, inter/intra-cell movement, reconfiguration, partial subcontracting, and inventory carrying costs. The first "value-at-risk" introduced by Group of 30 reports in July 1993. Origins of the name "value-at-risk" are murky. Several similar names were used during the 1990's, including: “dollars-at-risk" (DaR), “capital-at-risk" (CaR), "income-at-risk" (IaR), "earnings-at-risk" (EaR) and "value-at-risk" (VaR). It seemed that users liked the "-at-risk" moniker, but were uncomfortable labeling exactly what was "at risk".Guldimann (2000) suggests that the name "value-at-risk" originated within JP Morgan prior to 1985. JP Morgan publicized VaR to professionals at financial institutions and corporations with its Risk Metrics service[17] .Markowitz (1952) was the first to defines tradeoff between risk and return in portfolio selection as an optimization problem. He suggested choosing an asset mix such that the portfolio variance is minimum for a fixed target level of expected return.CVaR and its minimization formula were first developed by Rockafellar and Uryasev(2000). Uryasev and Rockafellar (2002) introduced a new approach to optimized a portfolio by calculating $\mathrm{VaR}$ and minimizing $\mathrm{CVaR}$ simultaneously to reduced risk of high losses[18].Sarykalin et al . demonstrate $\mathrm{VaR}$ and $\mathrm{CVaR}$ in risk management and optimization[6].Sawik Proposed a bi-objective mixed integer program model to selection of suppliers and the allocation of orders is based on price and quality of purchased parts and reliability of on time delivery To control the risk of delayed supplies, VaR and CVaR are applied[19].

\section{PROBLEM DESCRIPTION}

In this research we assume a cellular manufacturing system .The problem is to determined a plan to produce and subcontract parts at a minimum cost and to mitigate the impact of sub-contracting risk.. This research considers customers demands are assumed to be deterministic. In this research a risk-averse model of optimal the CMS design is considered with the two popular percentile measures of risk, $\mathrm{VaR}$ and $\mathrm{CVaR}$, applied to control the risk of high losses (risk of sub-contracting cost). VaR and CVaR, are briefly defined below [18][19]:

- Value-at-Risk (VaR) at a $100 \alpha \%$ confidence level is the targeted cost such that for $100 \alpha \%$ of the scenarios, the outcome will not exceed VaR. In other words, VaR is a decision variable based on the $\alpha$-percentile of costs, i.e., in $100(1-\alpha) \%$ of the scenarios, the outcome may exceed VaR. 
- Conditional Value-at-Risk (CVaR) at a $100 \alpha \%$ confidence level is the cost in the worst

$100(1-\alpha) \%$. In other words, we allow $100(1-\alpha) \%$ of the outcomes to exceed VaR, and the mean value of these outcomes is represented by CVaR.

Define $\mathrm{T}_{\mathbf{s}}$ as the tail cost for scenario $\mathrm{s}$, where tail cost is defined as the amount by which costs in scenario s exceed $\mathrm{VaR}$.

\subsection{Notation}

$$
\begin{array}{ll}
i & \text { index for part types } i=1, \ldots, P \\
j & \text { index for machine types } \quad j=1, \ldots, M \\
k & \text { index for manufacturing cells } k=1, \ldots, C \\
\mathrm{~S} & \text { index for sub-contracting scenarios } \mathrm{s}=1, \ldots, \mathrm{S}
\end{array}
$$

\section{Input parameters}

\section{$P \quad$ Number of parts}

$M \quad$ Number of machines

C Number of manufacturing cell

$a_{i j}$ Equals to 1 if part $\mathrm{i}$ require to be processed on machine $\mathrm{j} ; 0$ otherwise

$\propto_{j} \quad$ variable cost of machine type $\mathrm{j}$ for each unit time

$t_{i j}$ processing time required to produce of part type $\mathrm{i}$ on machine type $\mathrm{j}$

$\theta_{j} \quad$ constant cost of machine type $\mathrm{j}$

$\beta_{i s} \quad$ sub-contracted Penalty cost of part type i for scenario s

$P_{S} \quad$ Probability of sub-contracting scenario $\mathrm{s}$

$M_{\max } \quad$ Maximum number of machines permitted in a cell

$M_{\min } \quad$ Minimum number of machines permitted in a cell

$T_{j} \quad$ time-capacity of machine type $\mathrm{j}$ 
$D_{i} \quad$ demand for part i

$\alpha \quad$ confidence level

\section{Decision variables}

$x_{i k} \quad$ Equals to 1,if part i processed in cell k;0 otherwise

$y_{j k} \quad$ Equals to 1,if machine $\mathrm{j}$ assigned to cell $\mathrm{k} ; 0$ otherwise

$Q_{i} \quad$ number of demand of part $\mathrm{i}$ that their operation performed by a machine type $\mathrm{j}$ in cell $\mathrm{k}$

$Q_{i s} \quad$ number of part $\mathrm{i}$ to be subcontracted in scenario $\mathrm{s}$

$T_{s} \quad$ the non-negative amount by which total cost in scenario s exceeds VaR(tail cost)

VaR Value-at-Risk

\subsection{MATHEMATICAL MODEL}

\subsubsection{Minimization of Total costs(production Cost and machin constant cost and cost of} subcontracted parts)

In a risk-neutral operating condition the optimal CMS Design can be measured by the Total costs (production Cost and machin constant cost and cost of subcontracted parts).In this subsection mixed integer programming model is proposed for a risk-neutral of optimal CMS Design.

$\min \sum_{i=1}^{P} \sum_{j=1}^{M} \sum_{k=1}^{C} \propto_{j} Q_{i} t_{i j} a_{i j} X_{i k} Y_{j k}+\sum_{j=1}^{M} \sum_{k=1}^{C} Y_{j k} \theta_{j}+\sum_{i=1}^{P} \sum_{s=1}^{S} p_{s} \beta_{i s} Q_{i s}$

s.t:

$\sum_{k=1}^{C} X_{i k}=1 \quad i=1, \ldots, P$

$\sum_{k=1}^{C} Y_{j k}=1 \quad j=1, \ldots, M$

$\sum_{k=1}^{C} Y_{j k} \geq M_{\min } \quad k=1, \ldots, C$ 


$$
\begin{array}{ll}
\sum_{k=1}^{C} Y_{j k} \leq M_{\max } & k=1, \ldots, C \\
Q_{i}+Q_{i s}=D_{i} & i=1, \ldots, P \\
\sum_{i=1}^{P} Q_{i} t_{i j} \mathrm{a}_{i j} X_{i k} Y_{j k} \leq T_{j} Y_{j k} & \forall j, k \\
X_{i k}, Y_{j k} \in\{0,1\}, Q_{i}, Q_{i s} \geq 0 &
\end{array}
$$

\subsubsection{Minimization of worst (subcontracted parts) cost (CVaR)}

In this section a risk-averse model of optimal CMS Design is considered with the two popular percentile measures of risk, $\mathrm{VaR}$ and $\mathrm{CVaR}$, applied to control the risk of high losses. In this section mixed integer programming model is proposed to reduce the risk of subcontracted parts high costs.

$\min \left(V A R+\frac{1}{1-\propto} \sum_{s=1}^{S} p_{s} T_{S}\right)$

s.t:

Eqs (2),(3),(4),(5),(6),(7),(8)

$T_{s} \geq \sum_{i=1}^{P} \sum_{j=1}^{M} \sum_{k=1}^{C} \propto_{j} Q_{i} t_{i j} a_{i j} X_{i k} Y_{j k}+\sum_{j=1}^{M} \sum_{k=1}^{C} Y_{j k} \theta_{j}+\sum_{i=1}^{P} \beta_{i s} Q_{i s}-V A R \quad \forall s$

$T_{S} \geq 0, s \in S$

\subsubsection{Bi-objective to minimization of weighted sum of total cost and worst cost.}

In this section[19] a bi-objective is presented aimed at minimizing both objective functions simultaneously to balance total cost with the risk tolerance. Steuer [20] proved that for mixed integer programs, there may be portions of the nondominated set (near a weakly nondominated solution) that the weighted-sum approach is unable to compute, even if the complete parameterization on $\lambda$ is attempted.

Min $\lambda($ total cost $)+(1-\lambda)($ worst cost $)$

Where $0 \leq \lambda \leq 1$ 


$$
\begin{gathered}
\min \lambda\left[\sum_{i=1}^{P} \sum_{j=1}^{M} \sum_{k=1}^{C} \alpha_{j} Q_{i} t_{i j} a_{i j} X_{i k} Y_{j k}+\sum_{j=1}^{M} \sum_{k=1}^{C} Y_{j k} \theta_{j}+\sum_{i=1}^{P} \sum_{s=1}^{S} p_{s} \beta_{i s} Q_{i s}\right]+(1 \\
-\lambda)\left[\left(V A R+\frac{1}{1-\propto} \sum_{S=1}^{S} p_{s} T_{s}\right)\right]
\end{gathered}
$$

Eqs (2),(3),(4),(5),(6),(7),(8),(10),(11)

\subsection{LINEARIZATION}

The proposed model is a nonlinear Mixed-integer programming model .therefore we reformulate the model as Mixed-integer linear programming model with define the new variables $z_{i j k}$ to replace the $x_{j k} \cdot y_{i k} \cdot$

\subsubsection{Minimization of Total costs(production Cost and machin constant cost and cost} of subcontracted parts)

$\min \sum_{i=1}^{P} \sum_{j=1}^{M} \sum_{k=1}^{C} \propto_{j} Q_{i} t_{i j} a_{i j} z_{i j k}+\sum_{j=1}^{M} \sum_{k=1}^{C} Y_{j k} \theta_{j}+\sum_{i=1}^{P} \sum_{s=1}^{S} p_{s} \beta_{i s} Q_{i s}$

s.t:

Constraints (2),(3),(4),(5),(6),(8)

Constraint (7) is changed as follows:

$$
\begin{aligned}
& \sum_{i=1}^{P} Q_{i} t_{i j} a_{i j} z_{i j k} \leq T_{j} Y_{j k} \quad \forall j, k \\
& z_{i j k} \leq x_{i k} \quad \forall i, j, k \\
& z_{i j k} \leq y_{j k} \quad \forall i, j, k \\
& x_{i k}+y_{j k}-z_{i j k} \leq 1 \quad \forall i, j, k
\end{aligned}
$$


$\min \left(V A R+\frac{1}{1-\propto} \sum_{s=1}^{S} p_{s} T_{S}\right)$

s.t:

Eqs (2),(3),(4),(5),(6),(8),(11)

Constraints (7)and (10) are changed as follows:

$\sum_{i=1}^{P} Q_{i} t_{i j} a_{i j} z_{i j k} \leq T_{j} Y_{j k} \quad \forall j, k$

$\mathrm{T}_{\mathrm{s}} \geq \sum_{\mathrm{i}=1}^{\mathrm{P}} \sum_{\mathrm{j}=1}^{\mathrm{M}} \sum_{\mathrm{k}=1}^{\mathrm{C}} \propto_{\mathrm{j}} \mathrm{Q}_{\mathrm{i}} \mathrm{t}_{\mathrm{ij}} \mathrm{a}_{\mathrm{ij}} \mathrm{z}_{\mathrm{ijk}}+\sum_{\mathrm{j}=1}^{\mathrm{M}} \sum_{\mathrm{k}=1}^{\mathrm{C}} \mathrm{Y}_{\mathrm{jk}} \theta_{\mathrm{j}}+\sum_{\mathrm{i}=1}^{\mathrm{P}} \beta_{\mathrm{is}} \mathrm{Q}_{\mathrm{is}}-\mathrm{VAR} \quad \forall \mathrm{s}$

\subsubsection{Bi-objective to minimization of weighted sum of total cost and worst cost.}

$\min \lambda\left\lceil\sum_{i=1}^{P} \sum_{j=1}^{M} \sum_{k=1}^{C} \propto_{j} Q_{i} t_{i j} a_{i j} z_{i j k}+\sum_{j=1}^{M} \sum_{k=1}^{c} Y_{j k} \theta_{j}+\sum_{i=1}^{P} \sum_{s=1}^{s} p_{s} \beta_{i s} Q_{i s}\right\rceil+$

$(1-\lambda)\left[\left(\mathrm{VAR}+\frac{1}{1-\alpha} \sum_{\mathrm{s}=1}^{\mathrm{s}} \mathrm{p}_{\mathrm{s}} \mathrm{T}_{\mathrm{s}}\right)\right]$

Eqs (2),(3),(4),(5),(6),(8),(11)

Constraints (7)and (10) are changed as follows.

$\sum_{i=1}^{P} Q_{i} t_{i j} a_{i j} z_{i j k} \leq T_{j} Y_{j k} \quad \forall j, k$

$\mathrm{T}_{\mathrm{s}} \geq \sum_{\mathrm{i}=1}^{\mathrm{P}} \sum_{\mathrm{j}=1}^{\mathrm{M}} \sum_{\mathrm{k}=1}^{\mathrm{C}} \alpha_{\mathrm{j}} \mathrm{Q}_{\mathrm{i}} \mathrm{t}_{\mathrm{ij}} \mathrm{a}_{\mathrm{ij}} \mathrm{z}_{\mathrm{ijk}}+\sum_{\mathrm{j}=1}^{\mathrm{M}} \sum_{\mathrm{k}=1}^{\mathrm{C}} \mathrm{Y}_{\mathrm{jk}} \theta_{\mathrm{j}}+\sum_{\mathrm{i}=1}^{\mathrm{P}} \beta_{\mathrm{is}} \mathrm{Q}_{\mathrm{is}}-\mathrm{VAR} \quad \forall \mathrm{s}$

\section{COMPUTATIONAL EXAMPLE AND DISCUSSION OF RESULTS}

To verify the performance of the proposed models we generate a random example and solve by branch-and-bound (B\&B)method under the LINGO 8.0 software on a personal computer with $3 \mathrm{GHZ}$ and $512 \mathrm{MB}$ RAM.we suppose there are 6 parts and 3 machines and 2 cells and 
number of subcontract scenarios was equal to 3 with equal occurrence probability and parts demand was equal 1000 for each type.

Table 1. Solution results for risk-neutral model

\begin{tabular}{|c|c|c|c|c|c|c|}
\hline & \multicolumn{6}{|c|}{ Part type } \\
\hline & 2 & 3 & 4 & 5 & 6 & \\
\hline Produced by factory & $8^{167}$ & $\mathbf{0}$ & & 125 & 500 & $\mathbf{0}$ \\
\hline $\begin{array}{l}\text { Prepared by sub-contract } \\
\text { scenario } 1\end{array}$ & $0^{833}$ & $\mathbf{0}$ & & $\mathbf{0}$ & $\mathbf{0}$ & $\mathbf{0}$ \\
\hline $\begin{array}{c}\text { Prepared by sub-contract } \\
\text { scenario } 2\end{array}$ & $\mathbf{0}^{\mathbf{0}}$ & $\mathbf{0}$ & & $\mathbf{0}$ & $\mathbf{0}$ & $\mathbf{0}$ \\
\hline $\begin{array}{c}\text { Prepared by sub-contract } \\
\text { scenario } 3\end{array}$ & $\begin{array}{c}0 \\
992\end{array}$ & 0 & & 875 & 500 & 1000 \\
\hline Total demands & $\begin{array}{l}1000 \\
1000\end{array}$ & $\mathbf{0}$ & & 1000 & 1000 & 1000 \\
\hline
\end{tabular}

To verify the performance of the risk-neutral model, we solved a random example, as it can be seen in Table 1. we solved example to risk-averse model, Figure 2 shows different tails costs for each sub-contracte scenarios and sub-contracte scenario 3 has minimum tail cost. Note that solutions to single objective models risk-neutral and risk-averse are equivalent to the solutions of the weighted-sum program with $\lambda=1$ and $\lambda=0$, respectively[19].The tradeoff between the total cost and the worst cost with $\alpha=0.9$ is shown in Fig. 3. The results emphasize the effect of varying cost-risk preference of the decision maker.

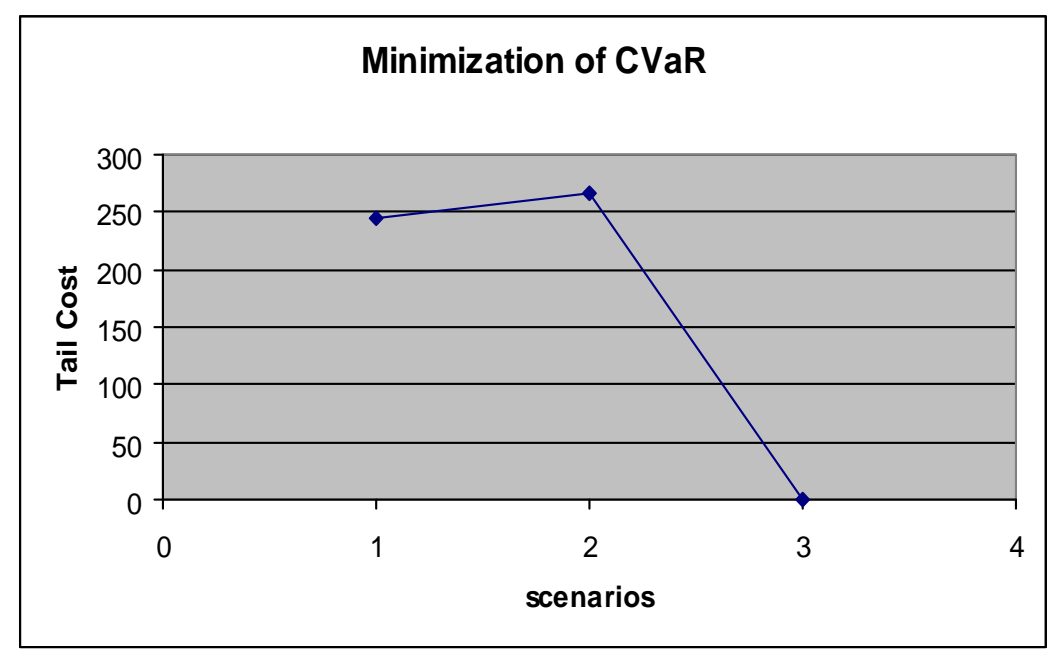


Fig. 2. Tail costs for different sub- contract scenarios

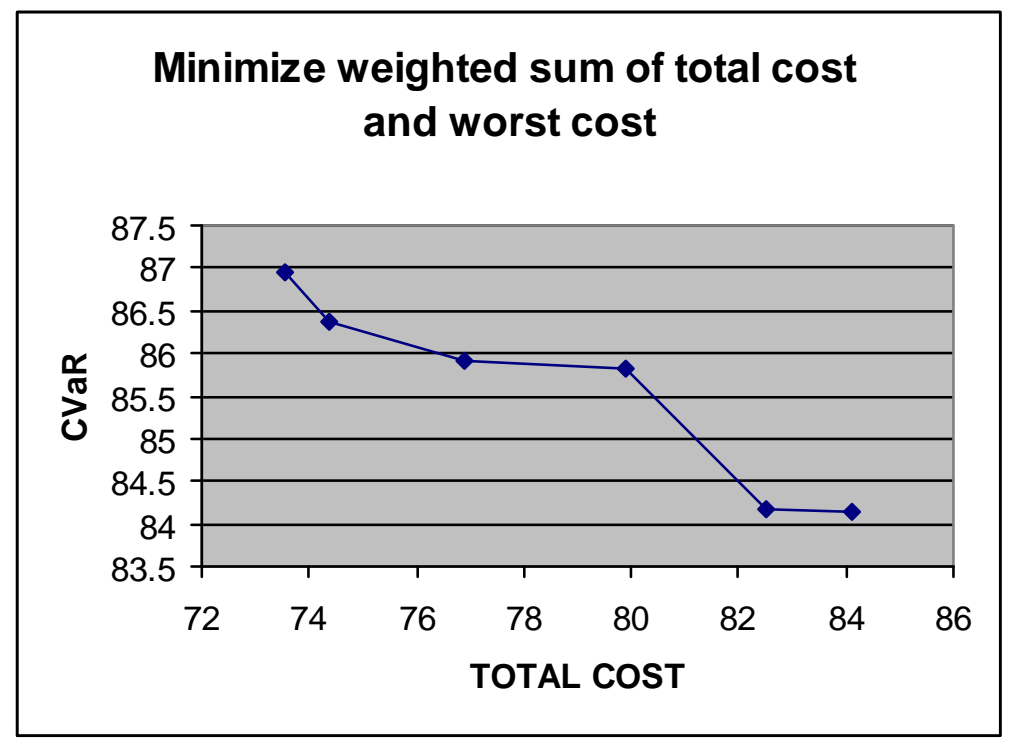

Fig.3. CVaRs for different Total costs

\section{CONCLUSION}

In this paper, we evaluate sub-contracting risk in a cellular manufacturing system design .the distinguishing feature of our model is its consideration of two popular measure of risk management ( $\mathrm{VaR}, \mathrm{CVaR})$ in the sub-contracting .the proposed risk-neutral model is capable of optimizing production Cost and machin constant cost and Penalty cost of subcontracted parts then we introduce risk averse model to minimizing worst cost of subcontracted parts with VaR and CVaR measures.finally trade-off model has been formulated as the optimization of a weighted-sum of total cost and the $\mathrm{CVaR}$ as a risk measure.solution results for a example shown scenario 3 with minimum amount of cost per each part has minimum of tail cost. ( tail cost is defined as the amount by which costs in scenarios exceed VaR).

\section{REFERENCES}

[1]. C. Caux, R. Bruniaux, H. Pierreval, Cell formation with alternative process plans and machine capacity constraints: A new combined approach, Int. J. Production Economics, 2000, $64,279-284$.

[2]. Nima S, Reza Tavakkoli-M, Integrated multi-period cell formation and subcontracting production planning in dynamic cellular manufacturing systems , Int. J. Production Economics, 2009,120, 301-314. 
[3]. A.Luntala. N, M. Diaby, W. L. Price, Hybrid genetic approach for solving large-scale capacitated cell formation problems with multiple routings. European Journal of Operational Research, 2006, 171, 1051-1070.

[4]. Anan mungwattana, Design of cellular manufacturing systems for Dynamic and uncertain production requirements with presence of routing Flexibility. PhD thesis, Virginia Polytechnic Institute and State University, September 1, 2000.

[5] J.H.Thun,D.Hoenig, An empirical analysis of supply chain risk management in the German automotive industry, Int. J. Production Economics, 2011, 131 : 242-249.

[6] S.Sarykalin, G.Serraino, S.Uryasev, Value-at-Risk vs. Conditional Value-at-Risk in Risk Management and Optimization, Tutorials in Operations Research,INFORMS 2008, 270-294. [7] R.T. Rockafellar, S. Uryasev, Optimization of conditional value-at-risk, The Journal of Risk, 2000, 2 (3): 21-41.

[8].Singh, N., 1993. Design of cellular manufacturing systems: An invited review. European Journal of Operational Research 69 (3), 281-511.

[9]. Atmani, A., Lashkari, R. S., \& Caron, R. J. A mathematical programming approach to joint cell formation and operation allocation in cellular manufacturing. International Journal of Production Research, 1995, 33, 1-15.

[10].Singh, N. Systems approach to computer-integrated design and manufacturing. New York: Wiley. 1996

[11].Wemmerlov, U., \& Johnson, D. J. Cellular manufacturing at 46 user plants: implementation experiences and performance improvements. International Journal of Production Research, 1997, 35, 29-49.

[12]. Chen, M. A mathematical programming model for system reconfiguration in a dynamic cellular manufacturing environment. Annals of Operations Research, 1998, 77, 109-128. [13].Selim, H.M., Askin, R.G., Vakharia, A.J. Cell Formation in group technology: Review, evaluation and direction for future research. Computers \&Industrial Engineering 1998, 34 (3), 3-20.

[14]. Lockwood, W., Mahmoodi, F., \& Mosier, C. Scheduling unbalanced cellular manufacturing systems with lot splitting.International Journal of Production Research, 2000, 38, 951-966.

[15].Chen, M. A model for integrated production planning in cellular manufacturing systems. Integrated Manufacturing Systems, 2001, 12, 275-284. 
[16]. Schaller, J. E., Erenguc, S. S., \& Vakharia, A. J. A mathematical approach for integrating the cell design and production planning decision. International Journal of Production Research, 2000, 38, 3953-3971.

[17] Holton, G, History of Value at Risk: 1922-1998, Boston, United States, Available at: http://www.contigencyanalysis.com. 2002

[18] T.Sawik, Selection of a dynamic supply portfolio in make-to-order environment with risks, Computers \& Operations Research, 2011, 38 : 782-796.

[19] T. Sawik, Supplier selection in make-to-order environment with risks, Mathematical and Computer Modelling, 2011 53: 1670-1679.

[20] R.E. Steuer, Multiple Criteria Optimization: Theory, Computation and Application, Wiley, New York, 1996.

How to cite this article:

Arghish O. Designing cellular manufacturing system under risk conditions. J. Fundam. Appl. Sci., 2016, 8(3S), 1308-1320. 